\title{
DEMOGRAPHIC, CLINICAL AND PARACLINICAL CHARACTERISTICS OF A SAMPLE OF EGYPTIAN MULTIPLE SCLEROSIS (MS) PATIENTS ATTENDING MS CLINIC IN AL-AZHAR UNIVERSITY HOSPITALS
}

\author{
By
Hussein Mohamed Hussein, Mohamed Farouk Aggag*, Wael Osman Mohamed, Mohie El-Din Tharwat Mohammad, Abd Allah Metwally Mahmoud $^{5}$ \\ Department of Neurology and Radiology*, Faculty of Medicine, Al-Azhar University, \\ Cairo, Egypt
}

Corresponding author: Abd Allah Metwally Mahmoud Abu-Obia,

Mobile: 01000707814,

Email: dr_Abdallah.metwally@yahoo.com

\begin{abstract}
Background: Multiple sclerosis is an autoimmune inflammatory demyelinating disorder, affecting people in the most productive period in their lives with more predilection to affect females more than males, many demographic studies of multiple sclerosis had been done in many western countries, in the middle east particularly in Arabic countries multiple sclerosis now being heavily studied in all aspects ofthe disorder after the incidence of multiple sclerosis has been increased.

Objective: The aim of this work was to study the clinical and paraclinical characteristics of patients with multiple sclerosis (MS) attending Al-azhar university hospitals, (Al-Hussein and Bab-El-Sherya) along the time of the study (from April 2017 to April 2019) aiming for better management and rehabilitation of Multiple sclerosis patients to improve their quality of life.

Patients and Methods: This was a cross sectional descriptive study carried on 400 definite multiple sclerosis patients who were recruited from Al-Azhar university hospitals diagnosed according to revised McDonald's criteria 2017.

Results: The current study included 400 MS patients, 113 were males and 287 were females, the main age of disease onset was $28.42 \pm 8.48$, the motor manifestations was the most common presenting manifestation, followed by optic neuritis then the sensory manifestations, the relapsing remitting phenotype was the commonest phenotype, the family history of MS was positive in $2 \%$ in the current study, we observed a statistically significant difference between MS patients as regard MS phenotype and the sex of the patient, age and the total EDSS, first clinical symptoms and the total EDSS, time to 2nd clinical event and the total EDSS and the lesions in the spinal cord and the total EDSS.
\end{abstract}

Conclusion: The first clinical presentation of MS affects the patient EDSS, patients with visual and sensory presentation had commonly lower EDSS, compared to patients with motor presentation had commonly higher EDSS.

Keywords: Egyptian, Demographic, Clinical data, Multiple Sclerosis. 


\section{INTRODUCTION}

Multiple sclerosis (MS) is the mostcommon autoimmune inflammatory demyelinating disorder of the central nervous system, with highly variable clinical presentations. Common symptoms and signs of MS include sensory symptoms in the limbs or face, unilateral (mainly) visual symptoms, sub-acute motor deficits, double vision, ataxia and gait disturbances, vertigo, bladder symptoms, and pain (Miller et al., 2012).

The main phenotypes of MS are relapsing and progressive disease.

About $85-90 \%$ of patients starting by relapsing-remitting (RRMS) course, with clinically isolated syndrome (CIS) presenting as the first demyelinating manifestation in the form of optic neuritis, motor symptoms, brainstem, and spinalCord symptoms (Miller et al., 2012).

Small percentage $(5-10 \%)$ of patients has primary progressive multiple sclerosis (PPMS) with progression from the start, mainly spinal-cord syndrome (Rice et al., 2013).

After the RRMS onset, by about 10-20 years some patients enter the secondary progressive phase of the disease where there is gradual worsening of disability (Lublin, 2013).

The epidemiology of MS has been studied extensively mainly for Western countries due to high prevalence of MS in Caucasians (Evans et al., 2013). Many reports indicate increasing disease prevalence in parts of the world with previously low prevalence (Alroughani, et al., 2014).
The aim of this work was to study the clinical and paraclinical characteristics of patients with multiple sclerosis attending Al-Azhar university hospitals, (AlHussein and Bab-El-Sherya) along the time of the study (24 months from April 2017 to April 2019) aiming for better management and rehabilitation of our patients to improve their quality of life.

\section{PATIENTS AND METHODS}

This study was a cross sectional descriptive carried on definite multiple sclerosis patients who were recruited from Al-Azhar university hospitals (Al-Huessin and Bab-El-Sherya) over 24 months from April 2017 to April 2019.

Inclusion criteria: All definite multiple sclerosis patients diagnosed as MS according to revised McDonald criteria 2017 (Thompson et al., 2017), both males and females were included.

\section{Exclusion criteria:}

1. Patients with other medical or metabolic conditions that can mimic MS clinically or radiologically.

2. Presence of other neurological conditions simulating MS clinically or radiologically.

\section{All patients were subjected to}

I. Clinical assessment of MS patients.

II. Radiological investigations: MRI brain (MS protocol) with contrast done for all patients and MRI cervical and dorsal with contrast done for 362 patients.

III. Neurophysiological investigations: Visual evoked potentials.

IV. Laboratory investigations: CSF oligoclonal band done only for 127 


\section{DEMOGRAPHIC, CLINICAL AND PARACLINICAL CHARACTERISTICS.... 389}

patients who are newly diagnosed or their diagnosis need to be confirmed by CSF examination.

Ethical Considerations: Data collection for this registry received written approval of the medical ethics committee of the Ethics Board of Al-Azhar University, school of medicine, and further investigations applied to our study group were medically consented by the patient himself.

\section{Statistical Analysis:}

Data were collected, revised coded and entered to the statistical package for social sciences (SPSS), version 20. Qualitative data were presented as number and percentages, while quantitative data were presented as mean, standard deviations and ranges. The comparisons between two groups with qualitative data were done using Chi-square test. The comparison between two groups regarding quantitative data with parametric distribution was done using Independent t-test. So, P-value was considered significant when $\mathrm{P}$ was $<0.05$.

\section{RESULTS}

The present study included 400 definite multiple sclerosis patient recruited from Al-Azhar University Hospitals (AlHussein and Bab-El-Sherya) from April 2017 to April 2019 (Table 1), They were 113 males and 287 females, Mean age of the disease onset was $28.42 \pm 8.48$, the most common presenting manifestation was motor weakness, the most common phenotype was relapsing remitting course, and the family history was positive for multiple sclerosis in only $2 \%$ of the study group.

About $2 / 3$ of patients were female and $1 / 3$ were male.

The mean age of the patients were $32.59 \pm 9.41$ years old, while the main age at disease onset was $28.42 \pm 8.48$ years old.
Most of the patients $(84.3 \%)$ started their disease between 18 to 40 years old.

First clinical manifestations were motor weakness, optic nerve affection, sensory, brain stem and cognitive affection respectively.

The most common MS phenotype was relapsing remitting multiple sclerosis (RRMS) followed by clinically isolated syndrome (CIS), then secondary progressive multiple sclerosis (SPMS) lastly primary progressive multiple sclerosis (PPMS).

Family history of MS was positive in only $2.0 \%$ of the study group. 
Table (1): Main Characteristics of the patients

\begin{tabular}{|l|l|}
\hline Parameter & Value \\
\hline Sex (Female: Male) & $287: 113$ \\
\hline AGE (years \pm SD) & $32.59 \pm 9.41$ \\
\hline AGE at Onset (years \pm SD) & $28.42 \pm 8.48$ \\
\hline Below 18 years N (\%) & $29(7.3 \%)$ \\
$18-40$ years N (\%) & $337(84.3 \%)$ \\
Above 40 years N (\%) & $34(8.5 \%)$ \\
\hline RRMS N (\%) & $321(80.3 \%)$ \\
SPMS N (\%) & $19(4.8 \%)$ \\
CIS N (\%) & $57(14.3 \%)$ \\
PPMS N (\%) & $3(0.8 \%)$ \\
\hline First Clinical Manifestations N (\%) \\
\hline Motor Weakness & $201(50.3 \%)$ \\
\hline Sensory Manifestation & $46(11.5 \%)$ \\
\hline Optic Neuritis & $90(22.5 \%)$ \\
\hline INO & $28(7.0 \%)$ \\
\hline Ataxia & $30(7.5 \%)$ \\
\hline Cognitive Affection & $2(0.5 \%)$ \\
\hline Oculomotor Affection & $3(0.75 \%)$ \\
\hline Family History of MS N (\%) \\
\hline Negative & $392(98.0 \%)$ \\
\hline Positive & $8(2.0 \%)$ \\
\hline RRMS: Relapsing Remitting Multiple Sclerosis, SPMS: \\
Secondary Progressive Multiple Sclerosis, CIS: Clinically \\
Isolated Syndrome, PPMS: Primary Progressive Multiple \\
Sclerosis, INO: Internuclear ophthalmoplegia. \\
\hline
\end{tabular}


DEMOGRAPHIC, CLINICAL AND PARACLINICAL CHARACTERISTICS...

Table (2): Correlation between different patient disease characteristic and clinical disability measured by EDSS

\begin{tabular}{|c|c|c|c|c|c|}
\hline Patient Characteristic & \multicolumn{2}{|c|}{$\begin{array}{l}\text { EDSS }(0-3) \\
(N)=290\end{array}$} & \multicolumn{2}{|c|}{$\begin{array}{l}\text { EDSS >3 } \\
(N)=110\end{array}$} & p-value \\
\hline Age in Years Mean \pm SD & \multicolumn{2}{|c|}{$31.28 \pm 9.00$} & \multicolumn{2}{|c|}{$36.02 \pm 9.64$} & 0.0001 \\
\hline \multicolumn{6}{|l|}{ First Presenting Symptom } \\
\hline Optic Neuritis & \multicolumn{2}{|c|}{$77(26.5 \%)$} & \multicolumn{2}{|c|}{$13(11.8 \%)$} & \multirow{7}{*}{0.0001} \\
\hline Sensory & \multicolumn{2}{|c|}{$40(13.8 \%)$} & \multicolumn{2}{|c|}{$6(5.5 \%)$} & \\
\hline Motor Weakness & \multicolumn{2}{|c|}{$121(41.7 \%)$} & \multicolumn{2}{|c|}{$80(72.7 \%)$} & \\
\hline INO & \multicolumn{2}{|c|}{$26(9.0 \%)$} & \multicolumn{2}{|c|}{$2(1.8 \%)$} & \\
\hline Ataxia & \multicolumn{2}{|c|}{$22(7.6 \%)$} & \multicolumn{2}{|c|}{$8(7.3 \%)$} & \\
\hline Cognitive Affection & \multicolumn{2}{|c|}{$1(0.3 \%)$} & \multicolumn{2}{|c|}{$1(.9 \%)$} & \\
\hline Oculomotor Affection & \multicolumn{2}{|c|}{$3(1 \%)$} & \multicolumn{2}{|c|}{$0(0.0 \%)$} & \\
\hline \multicolumn{6}{|l|}{ Clinical Phenotype } \\
\hline RRMS & 233 & $80.3 \%$ & 88 & $\begin{array}{l}80.0 \\
\%\end{array}$ & \multirow{4}{*}{0.0001} \\
\hline SPMS & 1 & $.3 \%$ & 18 & $\begin{array}{l}16.4 \\
\%\end{array}$ & \\
\hline CIS & 56 & $19.3 \%$ & 1 & $.9 \%$ & \\
\hline PPMS & 0 & $0.0 \%$ & 3 & $2.7 \%$ & \\
\hline \multicolumn{6}{|l|}{ DMT Given } \\
\hline No Treatment & 48 & $16.6 \%$ & 9 & $8.2 \%$ & \multirow{5}{*}{0.0001} \\
\hline INFB1a & 215 & $74.4 \%$ & 46 & $\begin{array}{l}41.8 \\
\%\end{array}$ & \\
\hline INFB1b & 16 & $5.5 \%$ & 9 & $8.2 \%$ & \\
\hline Finglomod & 10 & $3.5 \%$ & 32 & $\begin{array}{l}29.1 \\
\%\end{array}$ & \\
\hline Azathioprine & 0 & $0.0 \%$ & 6 & $5.5 \%$ & \\
\hline \multicolumn{6}{|c|}{$\begin{array}{l}\text { EDSS: Expanded Disability Status Scale, RRMS: Relapsing Remitting } \\
\text { Multiple Sclerosis, SPMS: Secondary Progressive Multiple Sclerosis, CIS: } \\
\text { Clinically Isolated Syndrome, PPMS: Primary Progressive Multiple Sclerosis, } \\
\text { INO: Internuclear ophthalmoplegia, DMT: Disease Modifying Treatment. }\end{array}$} \\
\hline
\end{tabular}

There was an inverse relationship between patient's age and the degree of disability being lower in young and higher in older age groups (Table 2).

In correlating the first clinical manifestations with the degree of disability measured by EDSS score there were highly significant relationship as patients started by motor and cognitive affection had high EDSS score than those started by sensory or optic nerve affection. There was inverse relationship between the time to 2nd clinical event and the EDSS score.

Patients with spinal cord affection and atrophy has high EDSS score compared to those without cord affection.

Highly significant relationship was observed when MS phenotype was 
correlated with the degree of disability measured be the EDSS score as relapsing courses was associated with lower EDSS score while progressive courses was associated with high EDSS score.

\section{DISCUSSION}

Multiple sclerosis is one of the autoimmune inflammatory diseases so like most autoimmune diseases the incidence always common in female than in males and this may be explained by the effects of sex hormones in the causation of these disorders.

The current results are in agreement with results of the study done in $\mathrm{Abu}$ Dhabi included 105 multiple sclerosis patients showed that male: female ratio was $1: 2.75$.

Overall, peak age of MS onset is only slightly higher in men ( 25 years) and then in women (24 years), with some suggestion that age at presentation is increasing over time (Schiess et al., 2014).

The current study showed the same results as the mean age of onset in men was $29.13 \pm 8.99$ and in female was 28.13 \pm 8.27. As regard mean age of patients in the current study, it was $32.59 \pm 9.41$ years old and the mean age of onset of disease was $28.42 \pm 8.48$ years old with peak age of onset between 18-40 years old (84.3\%) of all patients. The present result was in agreement with result of the Egyptian study in Cairo University that showed that mean age of onset of disease in female was $27.7 \pm 7.99$ years old, while in males was 29.02 2.63 (Hashim et al., 2010).

As regard clinical presentation, in the current study the most frequent presenting
As regard the type of disease modifying treatment (DMT) and the EDSS score there was highlysignificant relationship as patientsreceiving interferons has low EDSS score in comparison to those receiving cytotoxic drugs who has high EDSS score.

symptoms were motor (50.3\%), visual $(22.5 \%)$, sensory $(11.5 \%)$, and brainstem lesions $(15.25 \%)$. This may be explained by the fact that patients may not seek medical consultation in minor symptoms as sensory, mild cognitive or mild sphinctric affection as opposed by motor weakness the patient asked for medical consultation more rapidly.

This was in agreement with result of the Egyptian study in Cairo University showed that the highest clinical presentation was motor presentation followed by sensory, visual, brainstem and cerebellar lesions, and the least was sphincteric manifestations (Hashim et al., 2010).

In the current study, we found that $80.3 \%$ of patients had RRMS, $4.8 \%$ had SPMS, $0.8 \%$ had PPMS as the inflammatory component was much higher in the early disease stages than in the late stages where the degenerative changes take the upper hand as more and more axons being lost. These results were near to the results of the Egyptian study in Cairo University showed that the ratio between different courses as RRMS was $73.45 \%$, SPMS was 9.55 and PPMS was 17\%, (Hashim et al., 2010).

Also, our results that RRMS were 80.3 $\%$ these were in agreement with result of studies showed that percentage of RRMS in Dubai $(77 \%)$, Kuwait $(78 \%)$ and Qatar $(83 \%)$ Yet higher result in Jordan was 
DEMOGRAPHIC, CLINICAL AND PARACLINICAL CHARACTERISTICS... 393

$90 \%$ and lower result in KSA was $60 \%$ and Iraq was 66\%, The PPMS type in the current study was smaller than the previous studies (Dirk et al., 2013) which may be due to relatively small number in our study. As regard western countries, a study carried in Colombia showed that 65 $\%$ of patients were RRMS (Ojeda et al., 2009).

A positive family history of MS was present in $2 \%$ of patients in the current study. These results were near to the results in Lebanon that showed positive family history for MS in 5\% of patients, This variation in different countries may be related to the nature of marriage where the marriage in between close relatives is associated with high risk of developing diseases with genetic backgrounds like multiple sclerosis (Alroughani, et al., 2014).

Older age at onset is associated with a more rapid disability progression likely due to prevalence of the primary progressive disease course, age dependent degenerative processes, and dysfunction of repair mechanisms in older subjects. The present study showed that first clinical presentation affect future disability of patients such as patients presented by visual and sensory presentation had lower EDSS yet in patients presented by motor, brain stem, focal spinal and combined presentation had higher EDSS with significant relationship, also mean EDSS differ significantly according to their first clinical presentation. The current study revealed highly significant inverse relationship between the time to second clinical event and the total EDSS as the more time to 2 nd clinical manifestations reflect less inflammatory changes and slow disease progression. Spinal cord affection and atrophy of the cord demonstrated via spinal MRI examination is an important indicator of disease progression and more disability accumulation as measure by EDSS. Also, the correlation between MS phenotypes and EDSS showed a highly significant relation as relapsing MS is associated with lower EDSS where inflammatory changes is more than axon loss while progressive MS associated with axon loss and low chance for repair is associated with high EDSS score. In the current study the percentage of patients receiving Interferon was $71.5 \%$ compared to $14.3 \%$ did not receive any disease modifying drug and $3.5 \%$ on cytotoxic drug. We have high percent of patients did not receive any disease modifying drug due to financial causes and lack of efficient health insurance system for all patients and some patients presented in progressive stage of disease and the EDSS score is low in patient receiving disease modifying treatments (DMT) than in patient who receive no DMT which reflect the importance of early diagnosis and treatment of the patients.

\section{CONCLUSION}

The present study showed that, the first clinical presentation of MS affect the patient EDSS, patients with visual and sensory presentation had commonly lower EDSS, compared to patients with motor presentation had commonly higher EDSS.

\section{CONFLICTS OF INTEREST}

There are no conflicts of interest. 


\section{REFERENCES}

1. Thompson, AJ, Brenda L, Banwell, Barkhof F, William M and Coetzee, CT, (2018): pathophysiology and risk factors of multiple sclerosis. Lancet Neurology 17: (2,) 162-173.

2. Alroughani R, Ahmed SF, Behbahani R, Khan R, Thussu A and Alexander KJ (2014): Increasing prevalence and incidence rates of multiplesclerosis in Kuwait. Mult Scler., 20:543-547.

3. Dirk D, Danial M, Ahmed Al Tabouki, Rim M,Boulenouar M, Naveed A, Hassan AL, Atlantic D, Gayane $M$, Yahia ZB, Yasir O, Osama EL, Tageldin S, Sadaat K, Francisco Ruiz $M$ and Faiza I. (2013): Prevalence, demographics and clinical characteristics of multiple sclerosis in Qatar.Multiple Sclerosis Journal; (19): 816 820.

4. Evans C, Beland SG, Kulaga S, Wolfson C, Kingwell $E$ and Marriott J. (2013): Incidence and prevalence of multiple sclerosis in the Americas: asystematic review. Neuroepidemiology, 40:195-210.

5. Hashim S, El Tamawy M, Hamdy S, El MasryT. (2010): Epidemiology of multiple sclerosis in Egypt.Egypt $\mathbf{J}$ Neurol Psychiat Neurosurg., 47: 625-632.
6. Lublin FD, Reingold SC, Cohen JA, Cutter GR, Sorensen PS and Thompson AJ. (2014): Defining the clinical course of multiple sclerosis: the2013 revisions. Neurology, 83:278-286.

7. Miller DH, Chard DT and Ciccarelli O. (2012): Clinically isolated syndromes. Lancet Neurol., 11:157-169.

8. Ojeda E, Gomez R, Balaguera P, SuarezEscudero JC, Vicini J and Sanchez JL. (2009): Es la esclerosis multiple (EM) mas severaenantioque?nosqueencundiboyacences? Acta Neurologica Colombiana, 25:174-169.

9. Rice CM, Cottrell D, Wilkins $A$ and Scolding NJ. (2013): Primary progressive multiple sclerosis: progress and challenges. J NeurolNeurosurg Psychiatry., 84:1100-1106.

10. Schiess N, Fataftah T, Al-Kendi F, Szolics M. (2014): Characteristics of a cohort of MS patients in Abu Dhabi: how similar to the west? Multiple Sclerosis and Related Disorders, 3:760 -763. 


\section{DEMOGRAPHIC, CLINICAL AND PARACLINICAL CHARACTERISTICS... 395}

\section{الخصائص الديمو جر افية و الإكلينيكية و الإكلينيكية المساعدة لدي عبنة من مر ضـي التصلب المتناثر المصربين المثرددين على عبادات التصلب المتتاثربمستشفيات جامعة الأز هر}

حسين محمد حسين، محمد فاروق عجاج*، وائل عثمان محمد، محي الدين ثروت محمد، عبدالله متولي محمود

قسمي طب المخ والأعصاب والأشعة التثخيصية*ثكلية الطب (بنين) - جامعة الأزهر ـ القاهرة

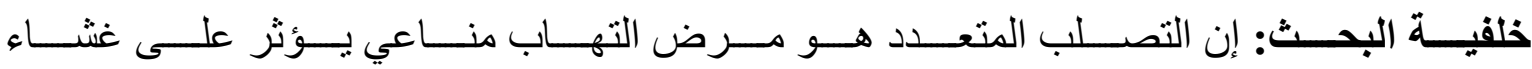

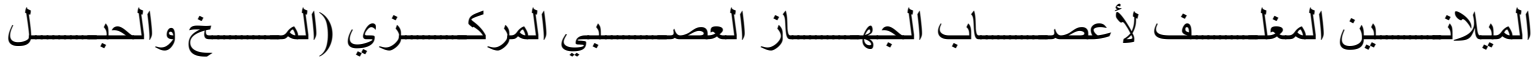

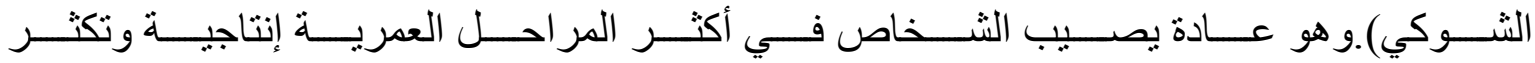

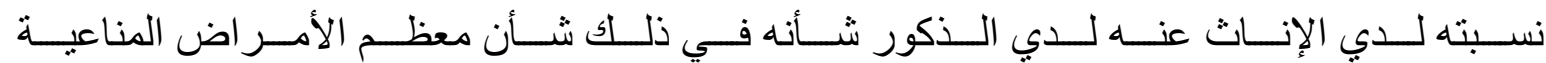

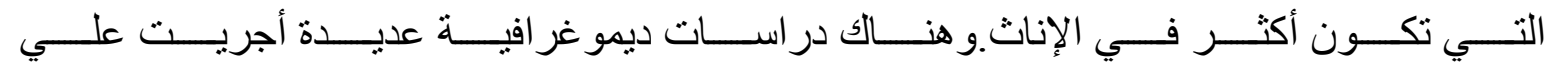
مرضي التصلب المتعدد في المجتمعات الغربية.

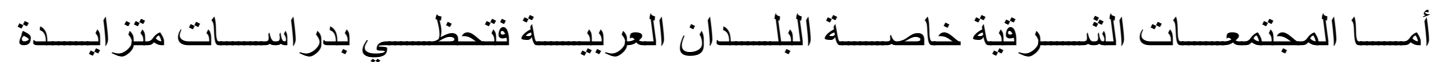

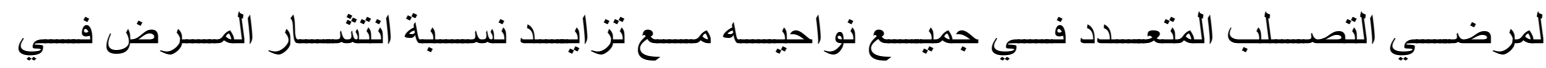
الأونة الأخيرة.

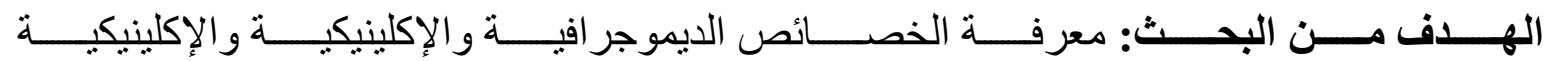

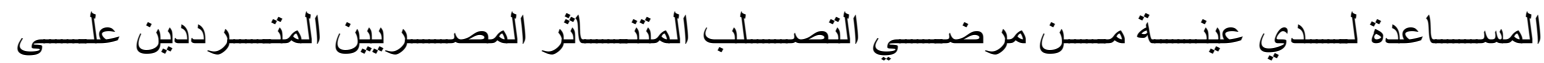

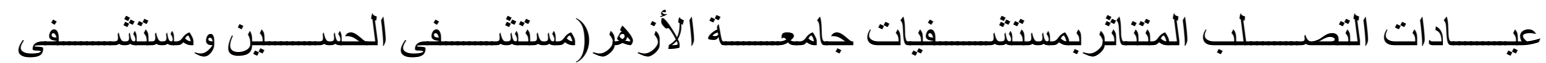
بــاب الثــعرية الجامعيــة) فــي الفتـرة مــن إبريــل 2017 إلــي مــن إبريــل 2019 للوقـوف علي خصائص المرض للارتقاء العلاجي و التأهيلي للمرضي المصابين.

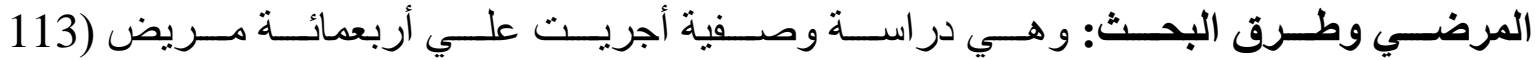

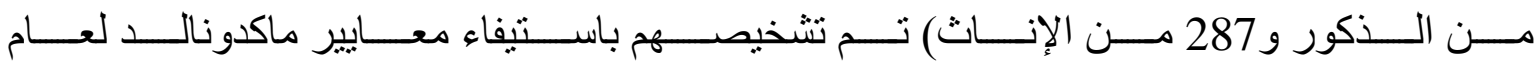




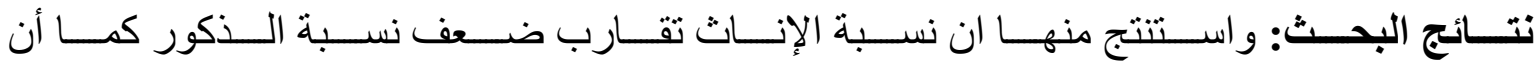

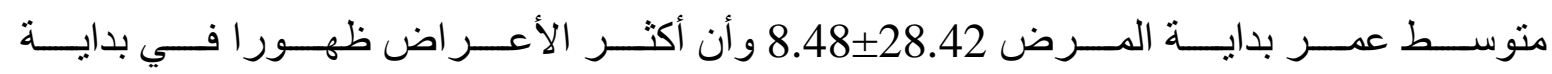

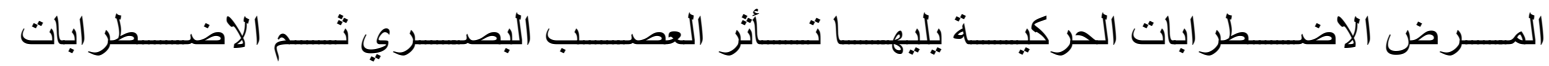

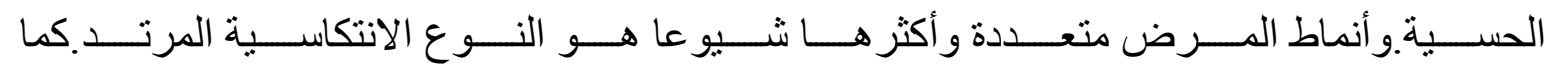

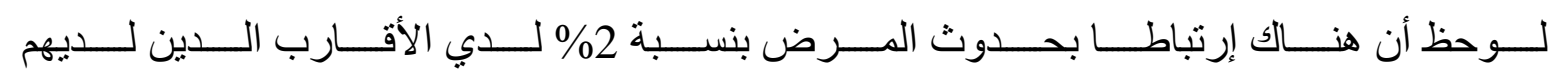

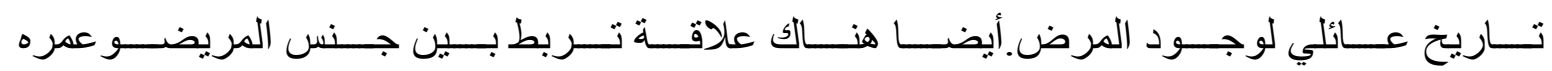

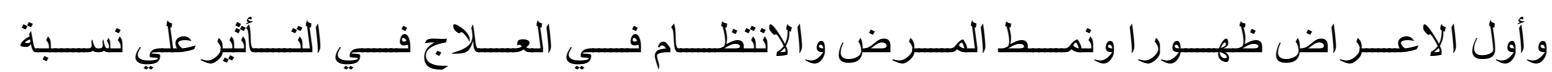
الإعاقة الناتجة عن المرض.

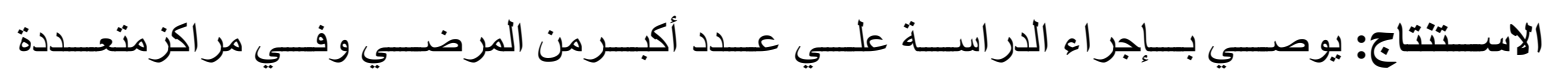
للوقوف علي رؤية أوضح لخصائص المرضي وطرق علاجهم المناسبة. 